\title{
Effect of Computer-Assisted Intervention on Early Phonological Processing Skills for Kindergarten Children in Hong Kong
}

\author{
Man Ching Law and Khe Foon Hew
}

\begin{abstract}
The present study investigates the effect of computer-assisted intervention targeting phonological processing skills in Hong Kong kindergarteners who learn English as a second language (ESL). Thirty children received 18 sessions of 45 minutes phonological processing skills intervention over nine weeks. Children in the experimental group $(n=15)$ received computer-assisted intervention, while the control group $(n=15)$ received intervention by traditional (pencil-and-paper) teaching approach. Following a pretest posttest - retention test design, participants were assessed for their phonological processing skills changes by alliteration test, blending test, phoneme segmentation test and rhyme test before the intervention, after the intervention and $\mathbf{1 0}$ weeks after the intervention. The results indicated that children in the experimental group outperformed than those in the control group in all subtests during the posttest. A retention test which held 10 weeks after the intervention revealed that significant gains in the experimental group were maintained in the alliteration test and rhyme test.
\end{abstract}

Index Terms-Computer-assisted intervention, CAI, early reading development, phonological processing skills.

\section{INTRODUCTION}

Over the past few decades, technology trends and the use of information technology (IT) to enhance teaching and learning has influenced the pedagogy in the education settings. Preliminary studies on IT in education mainly focused on the computer-assisted interventions (CAI) that were designed for medical use in helping children with learning difficulties. Computer-based tools were developed and used for training young children with autism, attention deficit hyperactivity disorder (ADHD), hearing problems or reading disabilities [1]-[3]. The positive effects of CAI on children with special educational needs has given rise to studies that attempted to integrate CAI into the curriculum across different subjects such as English, mathematics, physics and music [4]-[6]. Although considerable attention has been paid in the studies related to the use of IT at schools, little research has been done on the effectiveness of using CAI for language acquisition [7], [8].

The purpose of this research is to investigate the effect of computer-assisted intervention targeting phonological processing skills in Hong Kong kindergarteners who learn

Manuscript received October 25, 2016; revised February 15, 2017.

M. C. Law is with the University of Hong Kong, Hong Kong (e-mail: pixytess@hku.hk).

K. F. Hew is with the Faculty of Education, the University of Hong Kong, Hong Kong (e-mail:kfhew@hku.hk).
English as a second language (ESL). While previous clinical studies supported that CAI may improve phonological processing skills of young children with special educational needs, the present study aims to extend current literature by investigating the usefulness of CAI on children without learning difficulties. It is important to note that most of the existing studies are conducted in Western countries such as UK, America, Netherlands and Finland [9], [10]. In other words, few studies were conducted in Asia [11]. Therefore, the present study also serves as a first step in investigating CAI on kindergarteners in an Asian context.

\section{LITERATURE REVIEW}

Over the past few decades, there has been a continuing study on language learning in young children. Number of researchers and educators attempted to investigate the notion of alphabetic language acquisition at the late 1960s. Increasingly, researchers have begun to study how children acquire alphabetic languages by studying children's emergent literacy development.

\section{A. Early Reading Development and Phonological Processing Skills}

In studying early literacy development, educators were interested in the notion of how do children learn to read.

Ehri's four-phases reading acquisition model suggested that the process of acquiring alphabetic languages can be split into four phases, namely the pre-alphabetic phase, the partial-alphabetic phase, the full-alphabetic phase and the consolidated-alphabetic phase [12], [13]. She describes that each of the phase indicates a milestone of reading development in young children, from no knowledge to partial knowledge until full knowledge of reading. Ehri's comprehensive conceptual model does not only explain the process of how children learn alphabetical languages from letters, words to sentences, but it also highlights one of the key components towards proficient reading - the ability to recognize and manipulate phonemes in alphabetic languages to decode syllables and words. That is, the phonological processing skills.

Ehri's theoretical model was confirmed through empirical evidence. In 2000, Gallagher, Frith and Snowling [14] compared the early reading skills of 63 children with dyslexia and 34 children without reading impairment. The results revealed that training children with phonological processing skills is an effective teaching strategy to enhance early reading acquisition in young children. A few years later, Regtvoort and van der Leij [15] conducted another study to 
examine the letter knowledge and phoneme awareness for children at risk of dyslexia. The results were compatible with Gallagher, Frith and Snowling's study that phonological processing skills play an important role in facilitating early reading development in young children. Ecalle, Magnan and Calmus [16] also examined the effectiveness of phonological processing skills by comparing intervention results of two groups of kindergarteners who were trained with phonological teaching approach and whole word teaching approach. Along with the others, the findings highlighted that participants who were trained with phonological strategy outperformed than those in the whole word recognition group In addition, the significant impact of phonological training was found to have long-lasting effects.

To summarize, studies provided sufficient evidences to support the positive correlation between phonological processing skills and early literacy skills.

\section{B. CAIfor At-risk Children}

The importance of phonological processing skills in enhancing young children's reading development was highlighted by clinical studies. CAI has found to be particularly influential in training at-risk children's emergent literacy.

Mioduser, Tur-Kaspa and Leitner [17] demonstrated the effect of computer-based intervention in at-risk children. CAI was used to teach 46 pre-school children with high risk for learning disabilities in reading skills. Results suggested that such CAI treatment had significantly improved phonological awareness, word recognition, and letter naming skills of those children when compared to children taught with printed materials only. Additional evidence in support of the effectiveness of CAI is provided by Fälth, Gustafson, Tjus, Heimann and Svensson [18] in a recent study. In 2013, one hundred and thirty children with reading disabilities participated in a one-year longitudinal study. The study aims to examine the effects of CAI on enhancing children's phonological processing skills and reading abilities. Participants were divided into groups and received one of the following treatments: CAI training focused on phonological abilities, CAI training focused on word and sentence levels, a combined CAI training covered both mentioned topics, or an ordinary special educational needs training. The results appeared to be consistent with previous studies. Children in the CAI training groups were found to perform superior to those in the ordinary special training group in the posttest.

\section{CAI for Children without Learning Difficulties}

The significant benefit of CAI on children with special educational needs was supported by substantial studies. Yet, there has been an extensive discussion in the literature of whether such CAI can be broadly used in regular classroom and apply to children without reading disabilities.

For instance, Wild [19] undertook a study on the impact of using CAI with kindergarteners in the United Kingdom. 127 children aged 5-6 years old were selected as participants and allocated into one of the following groups: a group with phonological training and practice exercises using computer software, a group with phonological training but use paper-based format for exercises and another control group with no phonological training but worked on practical mathematics games. The result detected a greater improvement in phonological processing skills of children in the computer-based intervention group than those in the paper-based intervention group and the control group. More recently, Kyle, Kujala, Richardson, Lyytinen, \& Goswami [20] conducted another study to further investigate the effectiveness of CAI. Young children were randomly allocated into the control group or one of the CAI experimental groups (the experimental groups were trained with two different CAI phonological programs) as a 12 weeks intervention. The results of the posttest indicated that the positive phonological changes in participants of both CAI groups were better than those in the untrained control group. Moreover, the significant improvements lasted until four months after the intervention. Hence, the research appears to support the application of CAI on children without reading disabilities.

\section{CAI for Second Language Acquisition Learners}

With the growing number of studies documented the effectiveness of using CAI with non-at-risk children, researchers attempted to question the effectiveness of using CAI to enhance phonological processing skills on specific targets such as learners who learn English as a second language.

Segers and Verhoeven [21] further addressed the effectiveness of CAI of phonological processing skills in native and immigrant kindergarteners. 100 native and immigrant kindergarteners were randomly assigned into the experimental group and control group. Children in the experimental group were provided with a 15 minutes CAI session on phonological awareness weekly for the entire school year while children in the control group were provided with entertainment CAI that involved stories and games with shapes and colours. The rhyming, phonemic segmentation, auditory blending, and grapheme knowledge of children were examined in pre-test, interim test and post-test. Results reflected that there is a significant positive effect of early literacy in children who were trained with phonological CAI. Moreover, finding also shown significant positive effect of CAI on helping the immigrant children to catch up with the native children in phonological processing skills.

Until recent years, more and more advocates for educational reform attempted to compare the effectiveness of CAI on children with and without learning difficulties [22], [23]. However, literature concerning the effectiveness of CAI in improving early literacy skills of children without learning disabilities is still limited. In particular, little is known about the utilization of CAI for enhancing phonological processing skills of second language learners in kindergartens [24], [25]. Thus, the potential for using CAI to enhance second language kindergarteners' early reading skill needs to be investigated.

\section{METHODOLOGY}

\section{A. Research Questions}

The current study investigates the effectiveness of using computer-assisted intervention for training phonological processing skills on children who learn English as a second 
language (ESL) in Hong Kong. To that end, the addressed research questions are as follows:

1) Previous studies have shown that children with reading difficulties engage in CAI outperformed than those in the traditional (pencil-and-paper) teaching approach. Will the positive impact of CAI be applicable on children without special language learning needs?

2) Studies in the Western countries have shown that children engage in computer-assisted intervention outperformed than those in the traditional (pencil-and-paper) teaching approach. Will the positive effect of CAI be applicable on children in an Asian context?

3) Will the positive effect of CAI be retained for 10 weeks after the intervention?

4) What are the teacher's perceptions towards the impact of CAI?

\section{B. Design}

A pretest-posttest control and experimental group design was used in the present study. Besides, a retention-test was held 10-weeks after the intervention to examine the long-term retention effect of the intervention.

\section{Sampling}

A random sample of 30 students (11 boys and 19 girls) were recruited from a local preschool in Hong Kong. As reported by the school, phonological processing skills training was not included in the English curriculum.

Students were selected based on certain inclusion criteria: children are attending their final year at the kindergarten, they learn English as a second language, they did not receive regular phonological processing skills training at school, they should have no speech and hearing impairment, they should have never received or receiving any language related or speech and hearing therapy.

Among these 30 children, 28 of them were born in Hong Kong while the remaining 2 children were born in China. All children are Native-Chinese speakers who learn English as a second language. In addition, all children were reported with normal intelligence and normal speech and hearing abilities.

Stratified random sampling approach was used to ensure the desired representation of different ability learners were included in the control and experimental group. Hence, a selection assessment was used to measure all children's receptive vocabulary in English before allocating them into different groups.

\section{Measuring Instruments}

Two measuring instruments were selected and used in the present study.

An instrument named Peabody Picture Vocabulary Test, Fourth Edition (PPVT-4) [26] was used as selection assessment to measure all children's receptive vocabulary in English before allocating them into control and experimental groups. PPVT-4 is a norm-referenced instrument for assessing receptive vocabulary of individuals. The validity of this test is indubitable as it has been widely used by psychologists, researchers and educators for examining the acquisition of verbal abilities in young children since 1990s. The test includes 228 target items (vocabulary) which are ordered in sequences of increasing difficulty. Test administrator follows the basal and ceiling rules to assess children's vocabulary. The results of PPVT-4 were used as an index for categorizing the population into 3 small subgroups according to children's reading ability in English - high-ability, average-ability and low-ability group. After that, children were randomly selected from each ability group and assigned into either experimental group or control group. It is believed that such sampling design can reduce the likelihood of biases related to any demographic factors.

Besides, another instrument named Phonological Assessment Battery: 2nd Edition Primary (PhAB 2 Primary) [27] was also adopted in the present study for measuring early literacy phonological skills of young children. The full version of PhAB2 Primary consists of 10 subtests. Since some of the subtests assess content beyond this study, only 4 subtests - the alliteration test, the blending test, the phoneme segmentation test and the rhyme test - were adopted in the present study to measure the participants' phonological processing skills. Details of the truncated subtests are as follows:

Firstly, the alliteration test was used to assess a child's ability to isolate the initial sound in spoken words. For each testing item, a set of three pictures are shown to the examinee and spoken by the test administrator. Examinee is asked to choose two of the three words which start with the same initial letter sound. Examinee may give correct response by identifying the two alliterate words. Secondly, the blending test was used to assess a child's auditory blending skills, that is, the ability to combine letter sounds into spoken words. For each item in the test, the test administrator voices the phonemes and the examinee is expected to blend the sounds together into a complete word. A correct response is one that blends all the given phonemes to make a word. Thirdly, the phoneme segmentation test was used to assess a child's ability to separate spoken words into their constituent phonemes. Each target word is spoken by the test administrator and a picture is shown to the examinee to relieve the burden on working memory of young children. The examinee needs to listen, identify and break down all the phonemes in the word. Only productions of words which has been segmented into the correct phonemes can be marked as correct. Lastly, the rhyme test was used to assess a child's ability to identify phonologically salient sounds at the end of a word. For each item in the test, the examinee is shown to a set of three pictures spoken by the test administrator and asked to detect two rhyme words, in other words, the two words that end with the same sound. Correct responses can be marked only if the examinee identifies the two words that rhyme.

\section{E. Intervention}

In the present study, a phonics program named Jolly Phonics was adopted as the intervention. Empirical studies [28], [29] evidenced that Jolly Phonics helps young children in reading and writing in English through letter sounds training. In particular, it shows significant benefit in struggling children and children who learn English as a second language.

Jolly Phonics covers 42 letter sounds which include 
alphabet sounds and digraphs. These 42 letter sounds have been ordered in a specific sequence to aid learning. Each letter sound is provided with a story and linked to an action to keep young children actively involved and to help them remember the letter-sound correspondences more easily. Besides learning letter sounds, Jolly Phonics also emphasizes learning letter formation, blending words, identifying sounds in words and learning irregular spelling tricky words. The mentioned five basic skills are introduced, and sound-symbol relationships and skills of how to segment or synthesize sounds were taught gradually in Jolly Phonics to enhance children's phonological processing skills in early childhood.

The Jolly Phonics package contains comprehensive resources for teachers. The current study follows the suggested nine weeks teaching timetable provided in the package and the Jolly Phonics Games CD was selected as the training tool. Interactive computer games were used as teaching materials for children in experimental group while children in control group were taught with an identical set of teaching materials in printed format.

\section{F. Procedure}

All children were first tested with a selection assessment and divided into three ability subgroups according to their English competency. Children were randomly selected from each ability group when they were assigned into either experimental group or control group. A pre-test was undertaken to measure the children's alliteration, rhyming, blending and phoneme segmentation skills before the intervention.

An intervention was held two days per week over nine weeks and the duration of each training session was 45 minutes for both groups. Children in the experimental group and control group were taught with computer-assisted and pencil-and-paper teaching approach respectively. Children from both groups spent an equal amount of time for the intervention. Therefore, differences between the groups could not be related to the number of days or amount time spent.

A post-test was administered immediately after the intervention and a retention test was held 10 weeks after it to examine the phonological changes among the children.

\section{RESULT}

The repeated assessments of PhAB2 Primary were held before, after and 10 weeks after the intervention.

\section{A. Descriptive Data}

Table I presents the descriptive data (mean and standard deviation) of the four tests for the two groups.

A mixed between-within subjects analysis of variance (ANOVA) was conducted to assess the impact of the intervention (computer-assisted, pencil-and-paper) on kindergarteners' scores on each four test (Alliteration, Blending, Phoneme Segmentation, and Rhyme), across three time periods (pre-intervention, post- intervention and 10-week follow-up).

\section{B. Assumption Tests}

There were no outliers for each of the four tests, as assessed by examination of studentized residuals for values greater than \pm 3 . The assumption for homogeneity of variances for all tests was also met, as assessed by Box's test of equality of covariance matrices (Alliteration test, $\mathrm{p}=.635$; Blending test, $\mathrm{p}=.836$; Phoneme Segmentation test, $\mathrm{p}=.405$; Rhyme test, $\mathrm{p}=.352$ ). Mauchy's test of sphericity indicated that the assumption of sphericity was also met for each test (Alliteration test, $\chi^{2}(2)=.513, \mathrm{p}=.774$; Blending test, $\chi^{2}(2)=$ $3.040, \mathrm{p}=.219$; Phoneme Segmentation test, $\chi 2(2)=.213, \mathrm{p}$ $=.899 ;$ Rhyme test, $\left.\chi^{2}(2)=2.310, \mathrm{p}=.315\right)$.

TABLE I: DESCRIPTIVE DATA OF THE FOUR TESTS

\begin{tabular}{llccc}
\hline \hline \multirow{2}{*}{ Measures } & Group & \multicolumn{1}{c}{ Pre-test } & Post-test & $\begin{array}{c}\text { Retention } \\
\text { test }\end{array}$ \\
\cline { 3 - 5 } & & \multicolumn{1}{c}{$\mathrm{M}(\mathrm{SD})$} & $\mathrm{M}(\mathrm{SD})$ & $\mathrm{M}(\mathrm{SD})$ \\
\hline $\begin{array}{l}\text { Alliteration } \\
\text { test }\end{array}$ & $\begin{array}{l}\text { Experiment } \\
\text { Control }\end{array}$ & $86.60(5.95)$ & $100.40(8.09)$ & $96.93(9.79)$ \\
& & & & \\
Blending & Experiment & $81.00(3.07)$ & $89.33(7.93)$ & $83.47(6.40)$ \\
test & Control & $81.07(3.17)$ & $83.40(7.57)$ & $79.40(7.01)$ \\
& & & & \\
Phoneme & Experiment & $83.07(3.73)$ & $91.93(4.51)$ & $87.20(5.41)$ \\
Segm. test & Control & $83.07(3.90)$ & $86.20(8.07)$ & $83.47(7.72)$ \\
& & & & $88.00(7.49)$ \\
Rhyme test & Experiment & $80.47(5.55)$ & $102.27(7.80)$ & $97.20(8.72)$ \\
& Control & $79.13(7.65)$ & $92.20(13.26)$ & $81.93(10.11)$ \\
\hline \hline
\end{tabular}

\section{Alliteration Test}

The interaction effect between type of intervention and time on alliteration score was not statistically significant, $\mathrm{F}(2$, $56)=2.122, p=.129$, partial $\eta^{2}=.07$. Therefore, an analysis of the main effect for time was performed. There was a substantial main effect for time, $\mathrm{F}(2,56)=24.466, p<.001$, partial $\eta^{2}=.466$, with both groups showing an increase in mean alliteration scores from pre-intervention to post-intervention (Fig. 1). Both groups also showed a slight decrease in alliteration scores from post- intervention to 10-week follow up.

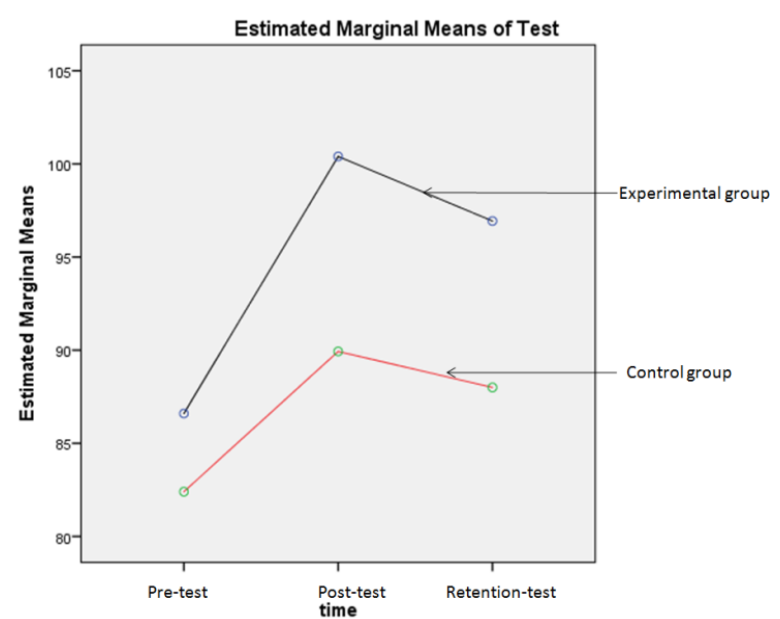

Fig. 1. Profile plots for alliteration test.

The main effect of group showed that there was a statistically significant difference in mean alliteration score between intervention groups $\mathrm{F}(1,28)=12.754, \mathrm{p}=.001$, partial $\eta^{2}=.313$, which was indicative of a large effect size. Specifically, the computer-assisted group $(\mathrm{M}=100.40, \mathrm{SD}=$ 8.09) was found to be more effective than the traditional teaching approach $(\mathrm{M}=89.93, \mathrm{SD}=8.00)$ for improving the 
alliteration skill (post-test score), $\mathrm{F}(1,28)=12.693, \mathrm{p}=.001$, partial $\eta 2=.312$. This positive effect persisted even 10 weeks after the intervention (retention test score) with the computerassisted group $(\mathrm{M}=96.93, \mathrm{SD}=9.79)$ outperforming the control group $(\mathrm{M}=88.00, \mathrm{SD}=7.49), \mathrm{F}(1,28)=7.879, \mathrm{p}$ $=.009$, partial $\eta^{2}=.220$. There was no significant difference in alliteration score between the experimental and control groups at the pre-test, $\mathrm{F}(1,28)=3.014, \mathrm{p}=.094$, partial $\eta 2$ $=.097$.

\section{Blending Test}

The interaction effect between type of intervention and time on blending test score was not statistically significant, $\mathrm{F}(2,56)=3.064, \mathrm{p}=.055$, partial $\eta^{2}=.099$. The main effect of time showed a statistically significant difference in mean blending scores at different time points, $F(2,56)=11.469$, $p$ $<.001$, partial $\eta^{2}=.291$. Both experimental and control groups showed an increase in mean blending scores from pre-intervention to post-intervention (Fig. 2). But both groups later on showed a decrease in blending scores from post-intervention to 10 -week follow up. The main effect comparing the two types of intervention was not significant, $\mathrm{F}(1,28)=3.589, \mathrm{p}=.069$, partial $\eta^{2}=.114$, suggesting no difference in the effectiveness of the two teaching approaches (computer-assisted and traditional) for teaching blending skill.

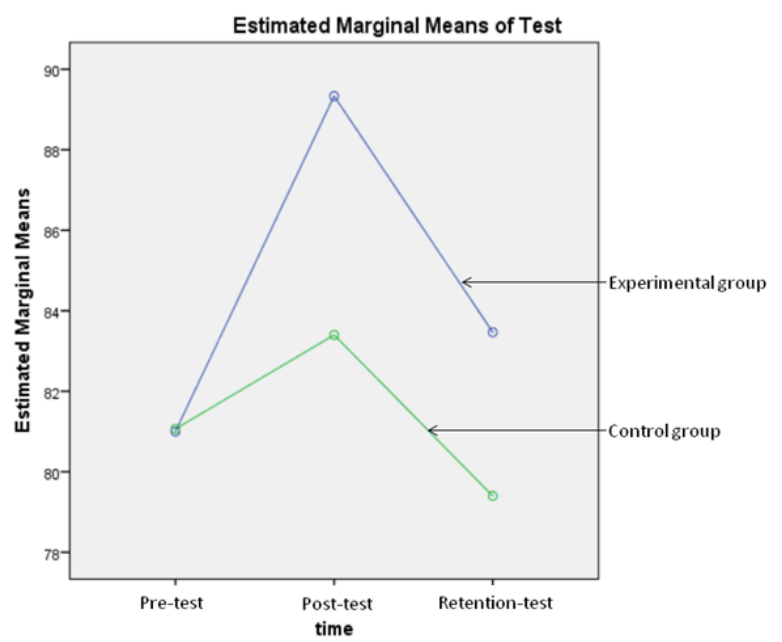

Fig. 2. Profile plots for blending test.

\section{E. Phoneme Segmentation Test}

There was a statistically significant interaction between the type of intervention and time on phoneme segmentation score, $\mathrm{F}(2,56)=3.689, \mathrm{p}=.031$, partial $\eta^{2}=.116$. Therefore, simple main effect for group was conducted. The phone segmentation post-test score was statistically significantly greater in the computer-assisted group compared to the control group, $\mathrm{F}(1,28)=5.765, \mathrm{p}=.023$, partial $\eta^{2}=.171$. There were no significant differences in phoneme segmentation scores between the experimental and control groups at the pre-test, $\mathrm{F}(1,28)=0.000, \mathrm{p}=1.000$, as well as the retention tests, $\mathrm{F}(1,28)=2.353, \mathrm{p}=.136$, partial $\eta^{2}=.078$. We also conducted a simple main effect test for time. There was a statistically significant effect of time on phoneme segmentation score for the computer-assisted group, $\mathrm{F}(2,28)$ $=23.933, \mathrm{p}<.001$, partial $\eta^{2}=.649$. Specifically for the computer-assisted group, phoneme segmentation score significantly improved at post- test compared to the pre-test (Mdiff $=8.87, \mathrm{SE}=1.02, \mathrm{p}<.001)$. There was also a significant improvement at the retention test compared to the pre-test $(\mathrm{Mdiff}=4.13, \mathrm{SE}=1.32, \mathrm{p}=.022)$. In contrast, there was no significant effect of time on phoneme segmentation score for the control group, $\mathrm{F}(2,28)=1.892, \mathrm{p}=.169$, partial $\eta^{2}=.119$. Fig. 3 shows the profile plots for both the experimental and control groups.

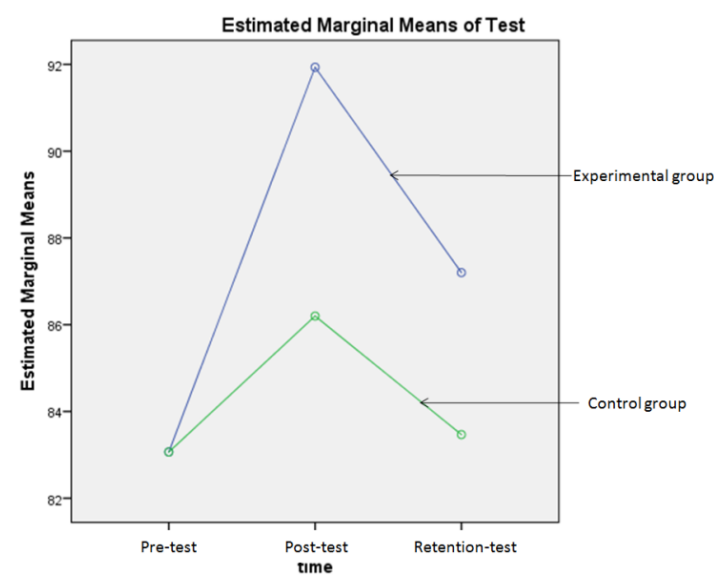

Fig. 3. Profile plots for phoneme segmentation test.

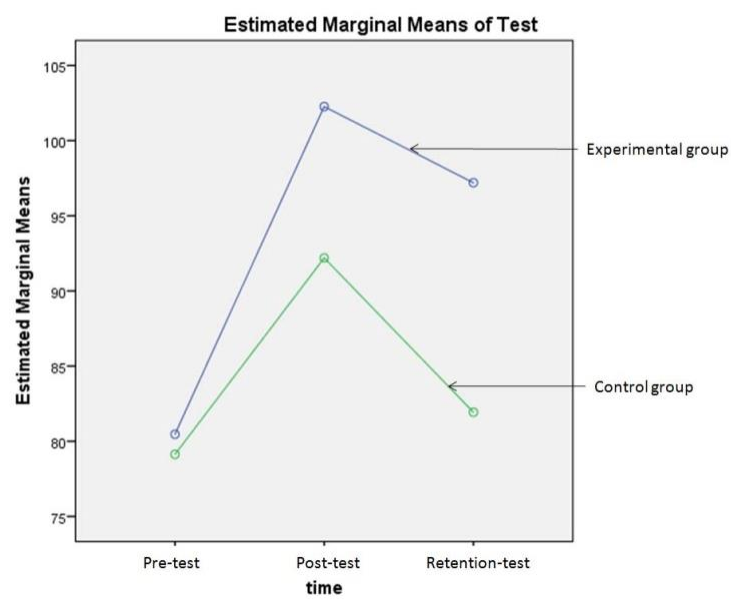

Fig. 4. Profile plots for rhyme test.

\section{F. Rhyme Test}

There was a statistically significant interaction between the type of intervention and time on rhyme score, $\mathrm{F}(2,56)=$ $5.257, p=.008$, partial $\eta^{2}=.158$. Results of the simple main effect test for group showed that the rhyme post-test score was significantly greater in the computer-assisted group compared to the control group, $\mathrm{F}(1,28)=6.423$, $\mathrm{p}=.017$, partial $\eta^{2}=.187$. The computer-assisted group also showed greater rhyme retention score at 10 weeks after the intervention than the control group, $\mathrm{F}(1,28)=19.615$, $\mathrm{p}$ $<.001$, partial $\eta^{2}=.412$. There were no significant differences in rhyme score between both groups at the pre-test, $\mathrm{F}(1,28)=$ $0.298, \mathrm{p}=.589$, partial $\eta^{2}=.011$. We also conducted a simple main effect test for time. There was a statistically significant effect of time on rhyme score for the computer- assisted group, $\mathrm{F}(2,28)=46.270, \mathrm{p}<.001$, partial $\eta^{2}=.768$. Specifically for the computer-assisted group, rhyme score significantly improved at post-test compared to the pre-test (Mdiff $=21.8, \mathrm{SE}=2.37, \mathrm{p}<.001)$. There was also a 
significant improvement at the retention test compared to the pre-test $(\mathrm{Mdiff}=16.73, \mathrm{SE}=2.48, \mathrm{p}<.001)$. For the control group, there was a significant effect of time on rhyme score, $\mathrm{F}(2,28)=7.152, \mathrm{p}=.003$, partial $\eta^{2}=.338$. The rhyme score significantly improved at post-test compared to the pre-test in the control group (Mdiff $=13.07, \mathrm{SE}=3.87, \mathrm{p}=.014$ ). However, the retention test failed to reach a significant difference when compared to the pre-test in the control group, (Mdiff $=2.8, \mathrm{SE}=2.72, \mathrm{p}=.964$ ). Figure 4 shows the profile plots for both the experimental and control groups.

\section{G. Summary of Results}

Results indicated that there were no significant differences between all the tests of the experimental and control groups before the intervention. This suggests that the students had similar initial phonological processing skills. Subsequent analyses revealed that the computer-assisted intervention had a statistically significant effect on improving the students' alliteration, phoneme segmentation, and rhyme skills at the conclusion of the project (i.e., post-test) compared to the control group. Furthermore, the effectiveness of significantly improving students' alliteration and rhyme skills with computer-assisted intervention remained sustained 10 weeks after the intervention. On the other hand, there were no significant differences in the effectiveness of the two teaching approaches (computer-assisted and traditional) for improving blending and phoneme segmentation skills 10 weeks after the intervention ended.

\section{DISCUSSION AND IMPLICATIONS}

\section{A. Discussion}

The current study aims to investigate the effectiveness and sustainability of the computer-assisted intervention.

Base on preceding literature, four research questions were addressed in Section III. The first question concerns with the subjects. As mentioned, all the subjects in the present study are children without language learning difficulties. The result of the post-test indicates that the experimental group outperformed than the control group after receiving the intervention of phonological processing skills, it reflects that the positive effect of CAI is consistent with previous clinical studies which involved children with special learning needs. Hence, we may conclude that the positive impact of computer-assisted intervention does not only appear on children with language learning difficulties, but also beneficial to children without special language learning needs. These results can be explained by considering the advantages of teaching with information technology. Young children are more sensitive to multi-sensory information presented by computer games than spoken words by teachers. Since the games in CAI deliver pictures, written texts, audio narrations and animations simultaneously, the multi-sensory information may help to obtain children's attention, stimulate children's interest and improve children's concentration. Children tend to have ambition and desire to learn and practice phonological processing skills by playing educational computer games rather than doing repeated verbal practice or written exercises [30], [31].

The second question concerns with the regional issue.
Although most of the earlier studies that supported the positive impact of CAI were conducted in Western countries, the present study attempts to carry out the research in an Asian city - Hong Kong. According to the result of the post-test, students trained with CAI had significant positive effect in gaining phonological processing skills when compare to the students in the group of traditional teaching approach. This finding may provide evidence to the idea that CAI can be practically implemented and improved the efficiency of learning phonological processing skills in children in Asia. In other words, the effectiveness of CAI seems to be universal across region.

The third research question concerns about the persistency of CAI. A substantial body of research had documented the long-lasting effect of CAI in enhancing young children's phonological processing skills. However, the results of the current study were mixed. As mentioned, the significant difference between the results of the experimental group and control group only occurs in the alliteration and rhyme subtests during the retention test. On the other hand, the results of both groups were found to have no significant difference in the blending and phoneme segmentation subtests. Therefore, the finding should be treated circumspectly. One possible reason might be in relation to the nature of the subtests. Considering the nature of the four subtests, we could further categorize the subtests into two aspects: phoneme detection and phoneme production. Phoneme detection tests refer to the tests that a child will be given options and requested to identify the same phoneme in several words and select the correct target words [32]. Subtests such as alliteration (identify same initial sound in words) and rhyme (identify same final sound in words) tests are examples of phoneme detection tasks. Another type of measurement involves tasks that request phoneme production. Phoneme production tasks required phonological short-term memory which a child will be asked to follow certain instructions and response by producing words or sounds, for example, blending (to combine phonemes into a word), phoneme segmentation (separate words into individual phonemes) are tasks which involve phoneme production process [33]. Since phoneme production tasks demand a child's short-term memory and higher order linguistics ability more than the phoneme detection tasks, we could say that alliteration and rhyme subtests are easier tasks in the assessment while compare to the blending and phoneme segmentation tasks [34]. That could further explain why the children's performance in the alliteration and rhyme tests would be able to remain for longer time than the other two tests.

The last research question is related to the teacher's perspective towards CAI. The instructor has highlighted two drawbacks about the Jolly Phonics Games CD in the reflection report. The instructor reported that the buttons for accessing the game zones in the main menu are designed as images without labels. Since the images are embedded in the background, the buttons cannot be easily identified. It is suggested that adults may need to aid with individuals to find the buttons to access different game zones. Besides, the font sizes of the texts in most of the games are relatively small. It may result in affecting the performance of children who rely 
on visualizing printed-texts. Although there are disadvantages found in the computer games, the instructor reported several points that are worth highlighting. Firstly, the instructor reported that the digital games consist of texts, images, narrations, animations and background music. The multiple use of medias may help children to learn in a multi-sensory way, catch young children's attention and build their interest in learning. Hence, children in the experimental group appear to be more attentive and responsive than those in the control group during the intervention. Secondly, the design of the games is child friendly. Even though children were not given marks in the games, certain encouraging narrations and animations will only be activated by correct answers. On the other hand, if wrong answer is presented, either a second chance will be given with clues provided or a correct answer will be displayed. These prompt responses to the player may allow children to learn from experience and enhance children's motivation to practice and finish the tasks.

The answers for the research questions above could serve as a basis on reviewing the impact of CAI in a local context.

\section{B. Implications}

Taken together, a few implications can be drawn from the current study. The findings suggest that after the intervention, a significant improvement in phonological processing skills was obtained in children who attended the computer- assisted intervention when compare to those in the group of traditional teaching approach. This implies that CAI significantly contributes to the success of learning phonological processing skills in ESL young children without special learning difficulties. Such finding is seen to provide empirical evidence to support the popular belief that e-learning might help in teaching early literacy development. The findings in the present study suggest the possibilities for the wide spread utilizing of computer-integrated teaching strategy for language acquisition in kindergartens. The significant impact attributable to the computer-assisted teaching approach result could be taken as evidence for the government boards, administrators, educators and teachers to re-consider the design of teaching plans and make wide use of computer technology for all young learners while teaching early literacy reading skills in kindergartens.

\section{CONCLUSION}

\section{A. Main Findings}

In this study, the results of the investigation on the impact of computer-assisted intervention on phonological processing skills for kindergarten children in Hong Kong were presented. Two of these findings are worth summarizing:

First, the results of the current study are in line with those reported for at-risk readers or children with learning difficulties in previous clinical studies. The present study enhances earlier studies' findings by extending the population scope towards children without special language learning needs. Results in the current study suggest that the positive effect of computer-assisted intervention is applicable not only on struggling readers but also on typical readers. This finding suggests the versatility of educational technology. Perhaps we may consider to further develop the CAI applications for universal education but not limited to specific medical use.

Second, within the extensive literature on CAI, most of them were conducted in Western countries whereas comparatively little research has focused on the investigation in Asian region. Since participants in the present study were selected from the population of a local kindergarten in Hong Kong, this study has taken a step to demonstrate the feasibility of CAI in Asian children. We may further interpret this as the universality of positive effect of CAI. It is suggested that CAI teaching approach is applicable for both Westerners and Asians. Therefore, such educational technology could be spread, promoted and endorsed in Asian regions.

\section{B. Limitations}

Even though the result may offer valuable insights into the effectiveness of computer-assisted intervention, some limitations of the present study should be noted.

The first limitation concerns with the sample size in the current study. The sample which consists with 30 children is relatively small. Besides, all the participants who participated in the present study were recruited from three classes in the same kindergarten. Therefore, the result may not be generalized to represent the entire population in Hong Kong.

The second limitation is related to the sample bias. Although both the experimental group and control group composed of 15 participants, majority of the children in the experimental group were female. To be more precise, as listed in Table 1, there are 11 females and 4 males in the experimental group while 7 male students and 8 female students were included in the control group. Since the sample was randomly selected from the population and the participants were allocated into the experimental or control group based on their reading ability levels so the participants in both groups may not follow the gender balance. Thus, the generalization of the results of this study is restricted to the sample in this targeted population.

The last limitation rooted in the short period allowed for the intervention. Participants of the current study intensively attended a 9-weeks intervention on training their phonological processing skills, yet, the learning process of early language and literacy development usually covers a much longer duration than this. In addition, it is very likely that children may develop their own early literacy skills at different rates. Therefore, the limited administer time for the current study may affect the interplay of CAI in enhancing children's phonological processing skills. To conclude, it is possible that some of the children may not demonstrate a remarkable learning progress in this study.

\section{Future Direction}

Findings reported in this paper have underscored the importance of using computer-assisted intervention for enhancing children's phonological processing skills. For children who were trained with computer-assisted teaching approach, a significant improvement in alliteration, blending, 
phoneme segmentation and rhyme skills was obtained after the intervention. Besides, the positive effect of CAI in training the alliteration and rhyme skills was retained 10 weeks after the intervention. Therefore, the study appears to support the superiority of CAI over traditional intervention in teaching phonological processing skills in young children during the early literacy development stage.

Notice that phonological processing ability is not the only skill which children need to manipulate for reading, more investigations are needed to examine the effects of computer-assisted intervention on phonological production skills or other reading- related skills, such as prior letter knowledge or semantics fluency. In addition, since participants in the present study are ESL learners who learn English as a second language, perhaps an additional interesting avenue of investigation might be to consider whether phonological processing skills would transfer across other languages.

\section{REFERENCES}

[1] E. Vandewalle, B. Boets, P. Ghesquie`re, and I. Zink, "Development of phonological processing skills in children with specific language impairment with and without literacy delay: A 3-year longitudinal study," J. Speech Lang. Hear. Res., vol. 55, no. 4, p. 1053, 2012.

[2] N. Saine, M. Lerkkanen, T. Ahonen, A. Tolvanen, and H. Lyytinen, "Computer-assisted remedial reading intervention for school beginners at risk for reading disability," Child Dev., vol. 82, no. 3, pp. 1013-1028, 2011.

[3] J. Mautone, "The effects of computer-assisted instruction on the mathematics performance and classroom behavior of children with ADHD," J. Of Atten. Disorders, vol. 9, no. 1, pp. 301-312, 2005.

[4] T. Rank, C. Warren, and T. Millum, Teaching English Using ICT, London: Continuum, 2011.

[5] C. Bardelle and P. Di Martino, "E-learning in secondary-tertiary transition in mathematics: for what purpose?" $Z D M$, vol. 44 , no. 6 , pp. 787-800, 2012.

[6] J. Sætre, "Teaching and learning music composition in primary school settings," IEEE Trans. Music Educ. Res., vol. 13, no. 1, pp. 29-50, 2011.

[7] P. Björn and P. Leppänen, "Accelerating decoding-related skills in poor readers learning a foreign language: A computer-based intervention," EPSY, vol. 33, no. 6, pp. 671-689, 2013.

[8] T. Connolly, M. Stansfield, and T. Hainey, "An alternate reality game for language learning: ARGuing for multilingual motivation," IEEE Trans Comput. \& Educ., vol. 57, no. 1, pp. 1389-1415, 2011.

[9] N. Saine, M. Lerkkanen, T. Ahonen, A. Tolvanen, and H. Lyytinen, "Computer-assisted remedial reading intervention for school beginners at risk for reading disability," Child Dev., vol. 82, no. 3, pp. 1013-1028, 2011.

[10] C. N. Mentzer, B. Lyxell, B. Sahlén, Ö. Dahlström, M. Lindgren, M. Ors, P. Kallioinen, and I. Uhlén, "Computer-assisted reading intervention with a phonics approach for children using cochlear implants or hearing aids," Scand. J. Psychol., vol. 55, no. 5, pp. 448-455, 2014

[11] T. Watson and K. Hempenstall, "Effects of a computer based beginning reading program on young children," AJET, vol. 24, no. 3, pp. 258-274, 2008.

[12] L. Ehri, "Phases of development in learning to read words by sight," $J$. Read. Res., vol. 18, no. 2, pp. 116-125, 1995.

[13] L. Ehri, "Learning to read and learning to spell," Top. Lang. Disord., vol. 20 , no. 3 , pp. 19-36, 2000.

[14] A. Gallagher, U. Frith and M. Snowling, "Precursors of literacy delay among children at genetic risk of dyslexia," J. Child Psychol. Psychiat., vol. 41, no. 2, pp. 203-213, 2000.

[15] A. Regtvoort and A. van der Leij, "Early intervention with children of dyslexic parents: Effects of computer-based reading instruction at home on literacy acquisition," Learn. Individ. Differ., vol. 17, no. 1, pp. 35-53, 2007.

[16] J. Ecalle, A. Magnan and C. Calmus, "Lasting effects on literacy skills with a computer-assisted learning using syllabic units in low-progress readers," Comput. \& Educ., vol. 52, no. 3, pp. 554-561, 2009.
[17] Mioduser, H. Tur-Kaspa, and I. Leitner, "The learning value of computer-based instruction of early reading skills," JCAL, vol. 16, no. 1 , pp. 54-63, 2001

[18] L. Fälth, S. Gustafson, T. Tjus, M. Heimann, and I. Svensson, "Computer-assisted interventions targeting reading skills of children with reading disabilities - A longitudinal study," Dyslexia, vol. 19, no. 1 , pp. 37-53, 2013

[19] M. Wild, "Using computer-aided instruction to support the systematic practice of phonological skills in beginning readers," J. Read Res., vol. 32, no. 4, pp. 413-432, 2009.

[20] F. Kyle, J. Kujala, U. Richardson, H. Lyytinen, and U. Goswami, "Assessing the effectiveness of two theoretically motivated computer-assisted reading interventions in the United Kingdom: GG Rime and GG Phoneme,” Read. Res. Quart., vol. 48, no. 1, pp. 61-76, 2013.

[21] E. Segers and L. Verhoeven, "Long-term effects of computer training of phonological awareness in kindergarten," J. Comput. Assist Lear., vol. 21, no. 1, pp. 17-27, 2005.

[22] K. Carson, G. Gillon, and T. Boustead, "Classroom phonological awareness instruction and literacy outcomes in the first year of school," Lang. Speech Hear Serv. Sch., vol. 44, no. 2, p. 147, 2013.

[23] P. Macaruso and A. Rodman, "Efficacy of Computer-assisted instruction for the development of early literacy skills in young children," Read Psychol., vol. 32, no. 2, pp. 172-196, 2011.

[24] E. Segers and L. Verhoeven, "Multimedia support of early literacy learning," Computers \& Education, vol. 39, no. 3, pp. 207-221, 2002.

[25] M. Stuart, "Getting ready for reading: Early phoneme awareness and phonics teaching improves reading and spelling in inner-city second language learners," Brit. J. Educ. Psychol., vol. 69, no. 4, pp. 587-605, 1999.

[26] L. Dunn and L. Dunn, Peabody Picture Vocabulary Test, Revised, Circle Pines, Minn.: American Guidance Service, 1981.

[27] S. Gibbs and S. Bodman, Phonological Assessment Battery: 2nd Edition Primary, UK: GL Assessment, 2014.

[28] K. Lenters, "No half measures: Reading instruction for young second-language learners," Read. Teach., vol. 58, no. 4, pp. 328-336, 2004.

[29] D. Wyse and U. Goswami, "Synthetic phonics and the teaching of reading," Br. Educ. Res. J., vol. 34, no. 6, pp. 691-710, 2008.

[30] N. Karweit, "Should we lengthen the school term?" Educ. Res., vol. 14, no. 6, p. 9,1985

[31] D. Leiblum. "Implementing computer-aided learning in a university environment: some practical advice to a cal agency," Educ. Technol., vol. 29, no. 2, pp. 27-31, 1989.

[32] J. Bowey, M. Cain, and S. Ryan, "A reading-level design study of phonological skills underlying fourth-grade children's word reading difficulties," Child Dev., vol. 63, no. 4, pp. 999-1011, 1992.

[33] C. Snow, M. Burns, and P. Griffin, Preventing Reading Difficulties in Young Children, Washington, DC: National Academy Press, 1998.

[34] E. Vandewalle, B. Boets, P. Ghesquie're, and I. Zink, "Development of phonological processing skills in children with specific language impairment with and without literacy delay: A 3-year longitudinal study," J. Speech. Lang. Hear. Res., vol. 55, no. 4, p. 1053, 2012.

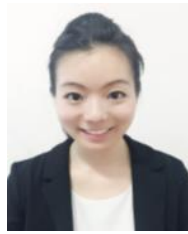

Man Ching Law is a graduate of the master of science information technology in education program at the University of Hong Kong and she holds a B.A. in linguistics from the University of Hong Kong. She worked as a kindergarten teacher to teach young children English as a second language in kindergartens and she is currently working in a non-governmental organization as a project officer to execute an educational project for students with culturally and linguistically diverse backgrounds.

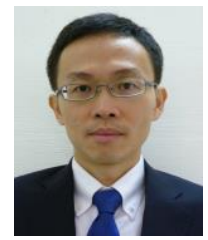

Khe Foon Hew is an associate professor of information and technology studies at the Faculty of Education, the University of Hong Kong. His research primarily focuses on computer-supported interaction, and technology-mediated learning. He has won several awards including the 2006 Educational Technology Research \& Development Young Scholar Award, the 2011 IGI Global 4th Annual Excellence in Research Journal Award, a Best Paper Award at the 2012 International Conference on ICT in Teaching and Learning, and a Best Presentation Award at the 2013 International Conference on Knowledge and Education Technology. 